\title{
RANCANGAN INSTALASI REGULATOR OTOMATIS UNTUK TUNGKU PENYANGRAIAN KOPI DAN KAKAO
}

\author{
Automatic Regulator Installation Design for Coffee and Cocoa Beans Roasting Furnace \\ Justus Elisa Loppies, Medan Yumas dan Endang Sri Rejeki \\ Balai Besar Industri Hasil Perkebunan \\ Jl. Prof. Dr. Abdurahman Basalamah No. 28, Makassar \\ Pos-el: justusloppies@gmail.com
}

\begin{abstract}
The aim of this study was to develop automatic regulator installations for coffee and cocoa beans roasting furnace. The developed furnace model consists of three main parts, namely the fireplace system, fuel control system and temperature control system. System performance was determined by observing the performance and deviation temperature and efficiency for operation at temperatures of $100-220^{\circ} \mathrm{C}$. The results of the roasting of coffee beans at temperatures of $160,180,200$ and $220^{\circ} \mathrm{C}$ for $9-40$ minutes and temperatures of 120 and $140^{\circ} \mathrm{C}$ for 45 minutes for cocoa beans showed stability and consistency with a temperature deviation of $1-3^{\circ} \mathrm{C}$. The efficiency of heat transfer in the coffee and cocoa roasting process ranges between $62.5-74 \%$ and $45-55 \%$ respectively, while the thermal efficiency for coffee roasting reaches $5-12 \%$ and for roasting cocoa was $8-10 \%$.
\end{abstract}

Keywords: automatic regulator installation, roasting furnace, control system, coffee and cocoa beans.

\begin{abstract}
Abstrak Penelitian ini bertujuan untuk mengembangkan instalasi regulator otomatis untuk tungku penyangraian biji kopi dan kakao. Model tungku bakar yang dikembangkan terdiri dari tiga bagian utama yaitu sistem perapian, sistem pengendali bahan bakar dan sistem pengendali suhu. Kinerja sistem ditentukan dengan mengamati capaian dan bias suhu dan efisiensi untuk pengoperasian pada suhu $100-220^{\circ} \mathrm{C}$. Hasil percobaan penyangraian biji kopi pada suhu 160, 180, 200 dan $220^{\circ} \mathrm{C}$ selama $9-40$ menit dan suhu 120 dan $140{ }^{\circ} \mathrm{C}$ selama 45 menit untuk biji kakao menunjukkan stabilitas dan konsistensi dengan bias suhu $1-3^{\circ} \mathrm{C}$. Efisiensi perpindahan panas pada proses penyangrain kopi dan kakao masingmasing berkisar antara $62,5-74 \%$ dan 45-55 \%, sedangkan efisiensi termal untuk penyangraian kopi mencapai 5-12\% dan untuk penyangraian kakao adalah 8-10\%.
\end{abstract}

Kata kunci: instalasi regulator otomatis, tungku penyangraian, sistem kontrol, biji kopi dan kakao.

\section{PENDAHULUAN}

Industri pengolahan pangan yang menggunakan bahan baku seperti bijibijian (kacang, kopi dan kakao), umumnya melakukan proses pematangan bahanbahan tersebut dengan cara penyangraian sebelum digunakan dalam proses pengolahan lanjutan. Tujuannya adalah untuk memberikan citra rasa, aroma dan warna tertentu pada produk yang disangrai.

Karakteristik produk yang diinginkan dari proses penyangraian ditentukan oleh suhu, waktu dan perlakuan proses yang diberikan. Kopi dan kakao memiliki karakteristik yang berbeda apabila diberi perlakuan penyangraian. Umumnya kopi disangrai selama 7-30 menit pada suhu 190-205 ${ }^{\circ} \mathrm{C}$ untuk menghasilkan tiga kualitas kopi yaitu light roast, medium roast dan dark roast. Penggorengan kopi pada suhu 180- $195^{\circ} \mathrm{C}$ menghasilkan kopi dengan kualitas light roast, kualitas medium roast dihasilkan dari penyangraian dengan suhu 200-210 ${ }^{\circ} \mathrm{C}$ sedangkan penyangraian dengan suhu 220-250 ${ }^{\circ} \mathrm{C}$ menghasilkan biji kopi dengan warna gelap (dark roast) (National Coffee Association, 1911). Penyangraian pada suhu 160 selama 12 menit menghasilkan biji kopi yang belum tersangrai (Lestari, 2016). Sedangkan kakao, umumnya disangrai pada suhu 120 dan $140{ }^{\circ} \mathrm{C}$ selama 45 menit sampai satu jam yang mana lebih rendah dari suhu penyangraian kopi (Beckett, 2000 dan Ziegleder, 2009). Dengan demikian, karakteristik kopi dan kakao yang dihasilkan dari proses penyangraian akan ditentukan berdasarkan suhu dan waktu yang terkendali secara spesifik dan akurat sehingga produk hasil sangrai memiliki kualitas dan karakteristik yang konsisten. 
Peralatan penyangraian yang ada umumnya menggunakan regulator dengan sistem pembakaran konvensional yang tidak menggunakan pengendali suhu sehingga sulit diperoleh hasil sangrai dengan karakteristik yang diinginkan. Regulator dengan sistem pembakaran langsung tanpa pengendali akan sulit digunakan untuk menetapkan hasil penggorengan (mis. kopi dan kakao) dengan klasifikasi tertentu. Klasifikasi produk sangrai yang dimaksud adalah ciri-ciri khusus berupa warna, cita rasa dan aroma tertentu yang dihasilkan dari suhu sangrai yang ditetapkan.

Secara teknis dan ekonomis sistem konvensional ini kurang menguntungkan karena terjadi bias suhu yang besar dan pemborosan energi dalam suatu proses pembakaran. Dibutuhkan sekitar 1,5-2 kg LPG untuk melakukan proses penyangraian 5-10 kg kakao pada suhu $120-140{ }^{\circ} \mathrm{C}$. Telah dikembangkan suatu metode yang dapat mengatasi bias dan inefisiensi dalam proses pembakaran yaitu dengan melakukan modifikasi pada sistem regulator yang ada melalui penambahan beberapa pengendali untuk memperkecil bias suhu dan mengatur penggunaan bahan bakar gas agar sesuai dengan kebutuhan. Pengendali dimaksud adalah dengan menempatkan sistem buka tutup otomatis pada saluran utama gas menggunakan solenoid. Solenoid berperan dalam mengatur kebutuhan bahan bakar gas berdasarkan adanya perintah dari sistem kontrol. Sistem kontrol merupakan pusat pengendali yang berperan menyampaikan informasi dari indikator suhu ke solenoid. Informasi yang disampaikan berupa jumlah bahan bakar gas yang dibutuhkan untuk mencapai suhu tertentu yang telah ditetapkan. Pada konsisi ini kontrol solenoid akan bekerja secara otomastis untuk mensuplai dan menghentikan pasokan gas ke tungku pembakaran. Gas yang menuju ke tungku pembakaran tediri atas dua bagian yaitu: 1) gas yang mengalir langsung dari tabung penampung gas melalui pipa kapiler (sistem kontinyu) dan 2) gas yang mengalir secara tidak langsung melalui katup solenoid (sistem terputus). Kedua sistem ini akan bekerja secara bergantian atau bersama-sama menyebabkan bias suhu menjadi kecil dan pasakon gas sebagai sumber bahan bakar menjadi efisien. Sistem ini perlu dikaji untuk diaplikasikan pada proses penyangraian dengan menggunakan suhu rendah antara $100-140{ }^{\circ} \mathrm{C}$ untuk penyangraian biji kakao dan pada suhu tinggi antara $150-220^{\circ} \mathrm{C}$ untuk penyangraian biji kopi.

Penelitian ini bertujuan untuk mengembangkan instalasi regulator otomatis untuk tungku penyangraian biji-bijian khusus untuk kopi dan kakao. Aplikasi pada proses penyangraian biji-bijian (kopi dan kakao) merupakan ukuran dari kinerja sistem kontrol ini dengan mengamati capaian dan bias suhu dan efisiensi untuk pengoperasian pada suhu $100-220^{\circ} \mathrm{C}$.

\section{METODOLOGI}

\section{Dasar Perancangan}

Sistem pengapian pada tungku pembakaran dapat dikendalikan dengan mengatur besar kecilnya energi panas yang diberikan melalui katup pengatur (solenoid). Jumlah energi panas berhubungan dengan besaran suhu yang dihasilkan. Untuk menghubungkan keduanya digunakan panel kontrol sebagai jembatan penghubung informasi. Pada panel kontrol ini, informasi besaran suhu yang dibutuhkan disampaikan ke solenoid untuk mengendalikan besaran energi panas yang diberikan agar tercapai suhu yang diinginkan. Besaran energi panas yang diberikan dilakukan dengan mekanisme buka-tutup gas oleh solenoid yang berada pada posisi by pass regulator.

\section{Alat dan Bahan \\ Rancangan instalasi regulator menggunakan beberapa alat yang terdiri dari: burner, regulator, valve (solenoid), panel listrik, panel kontrol, swicth handle, indikator suhu model RTD PT100, dan alat sangrai. Sedangkan bahan-bahan terdiri dari bahan untuk perancangan alat yang meliputi: kabel listrik 3 pas, pipa tembaga kapiler, pipa 0,5 inci, dan bahan-bahan untuk uji coba kinerja alat yaitu biji kopi dan biji kakao.}




\section{Metode Perancangan}

Model tungku bakar yang dikembangkan sebagaimana digambarkan pada blok diagram (Gambar 1) menggunakan sistem perapian yang terkendali dimana suplai LPG sebagai sumber bahan bakar diatur oleh sistem kontrol melalui selenoid setelah mendapat masukan (input) dari sensor suhu. Model perapian yang dirancang menggunakan sistem kontinyu dan sistem terputus. Pada sistem kontinyu, energi panas dalam jumlah kecil disuplai secara langsung tanpa melalui pengendali solenoid. Hal ini bertujuan agar proses pembakaran tidak terputus pada saat sumber panas utama terhenti. Pada sistem terputus, energi panas dalam jumlah besar dikendalikan oleh solenoid untuk mengatur besar kecilnya panas yang dibutuhkan. Perancangan sistem regulator ini dilakukan melalui beberapa tahap antara lain: identifikasi dan pengukuran, desain/pemodelan sistem dan penentuan dimensi, penyiapan alat dan bahan, rancang bangun, dan uji coba.

\section{Pengukuran Kinerja}

Pengukuran kinerja dilakukan dengan dua cara yaitu: 1) mengoperasikan instalasi regulator pada alat sangrai tanpa menggunakan bahan sangrai dengan suhu set point masing-masing 100, 120, 140, 160, 180,200 , dan $220^{\circ} \mathrm{C}$ dan 2) mengoperasikan instalasi regulator pada alat sangrai menggunakan bahan sangrai kopi dengan suhu set point $160,180,200$, dan $220^{\circ} \mathrm{C}$ dan penyangraian yang menggunakan bahan sangrai biji kakao dengan suhu set point 100,120 , dan $140{ }^{\circ} \mathrm{C}$. Kopi dan kakao yang digunakan dalam percobaan ini masingmasing sebanyak $10 \mathrm{~kg}$. Pada kedua cara ini dilakukan penetapan suhu operasi (set point) dan menentukan besaran bias suhu. Besaran suhu bias merupakan selisih antara suhu set point dengan suhu pengamatan (real). Selisih nilai suhu dimaksud adalah selisih nilai atas dan selisih nilai bawah dimana nilai atas merupakan suhu yang melebihi set point dan nilai bawah merupakan suhu yang kurang dari set point. Persamaan untuk menentukan bias suhu adalah:
$\mathrm{B}_{\mathrm{t}}=\mathrm{T}_{\mathrm{sp}}-\mathrm{T}_{\text {real }}$

Dimana $B_{t}$ adalah bias suhu; $T_{s p}$ adalah suhu set point dan $\mathrm{T}_{\text {real }}$ adalah suhu pengamatan. Selain itu dilakukan pengukuran suplai bahan bakar LPG, kalor (energi pembakaran), kebutuhan energi panas, efisiensi panas dan karakteristik produk sangrai. Formula untuk menentukan kebutuhan panas dan efisiensinya berdasarkan persamaan yang dikemukakan oleh Suharto (1991);

$Q_{1}=m_{c} \cdot c \cdot \Delta t$

dimana $Q_{1}$ adalah panas yang dibutuhkan untuk penyangraian bahan (kcal), $m_{c}$ adalah massa bahan yang disangrai $(\mathrm{kg})$, c adalah panas spesifik bahan yang disangrai $\left(\mathrm{kcal} / \mathrm{kg}^{\circ} \mathrm{C}\right)$, dan $\Delta \mathrm{t}$ adalah suhu penyangraian bahan $\left({ }^{\circ} \mathrm{C}\right)$.

Panas yang dibutuhkan untuk menguapkan air bahan adalah:

$Q_{2}=m_{w} L$

Dimana $Q_{2}$ adalah panas yang dibutuhkan untuk menguapkan air bahan yang disangrai, $m_{w}$ adalah air yang diuapkan $(\mathrm{kg})$, dan $\mathrm{L}$ adalah panas laten penguapan air (kcal/kg).

Efisiensi transfer panas dalam sistem penyangraian ditentukan dengan persamaan dari Schwartzberg (2014) dan Schwartzberg (2015):

$E_{h t}=\frac{T_{a i}-T_{a o}}{T_{a i}-T_{a}}$

Dimana $\mathrm{E}_{h t}$ adalah efisiensi perpindahan panas, $T_{a i}$ dan $T_{a o}$ adalah suhu penyangraian saat dimulai hingga mencapai suhu set point $\left({ }^{\circ} \mathrm{C}\right), \mathrm{T}_{\mathrm{a}}$ adalah suhu udara saat dimulai penyangraian. Efisiensi panas pada proses penyangraian ditentukan dengan persamaan dari Fellows (2000), dan EMT (2014):

$E=\frac{Q_{1}+Q_{2}}{Q_{\text {in }}}$

$Q_{\text {in }}=\mathrm{m}_{\mathrm{f}} \cdot \mathrm{C}_{\mathrm{f}}$

Dimana $E$ adalah efisiensi panas selama proses penyangraian, $Q_{\text {in }}$ adalah panas yang diberikan untuk proses penyangraian $(\mathrm{kcal}), \mathrm{m}_{\mathrm{f}}$ adalah kebutuhan 
bahan bakar LPG $(\mathrm{kg})$, dan $\mathrm{C}_{\mathrm{f}}$ adalah panas spesifik bahan bakar (kcal/kg).

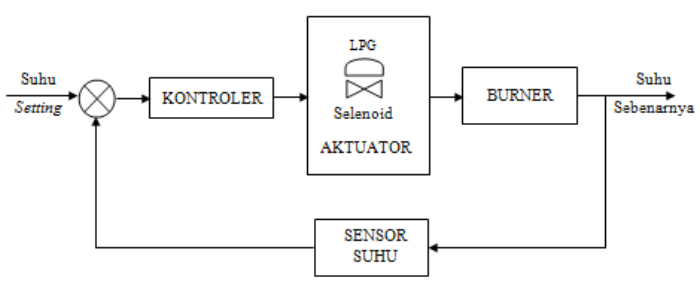

Gambar 1. Blok Diagram Sistem Regulator

\section{HASIL DAN PEMBAHASAN}

\section{Deskripsi Alat}

Instalasi regulator otomatis dengan model tungku bakar yang dikembangkan memiliki tiga bagian utama yaitu: sistem perapian/pembakaran, pengatur bahan bakar, dan piranti kontrol suhu (Gambar 2 dan 3).

Sistem pembakaran terdiri dari sebuah pipa utama (2) yang menghubungkan sumber bahan bakar (1) dengan sumber perapian (5) dimana pada bagian tengah dari pipa tersebut terpasang sebuah solenoid (3) sebagai pengendali bahan bakar. Posisi antara sumber bahan bakar dan solenoid terdapat percabangan dari pipa utama ke pipa kapiler (4) yang menuju ke ujung tungku perapian (5). Fungsi dari pipa kapiler ini adalah untuk menyalurkan bahan bakar secara secara kontinyu ke tungku perapian sehingga proses perapian tetap berlangsung selama proses penyangraian. Solenoid pada pipa utama dihubungkan dengan sebuah piranti kontrol suhu berupa panel (6) yang terhubung dengan sensor suhu (7).

Mekanisme kerja sistem dapat digambarkan sebagai berikut:

- Pada saat dimulai pembakaran, sistem kontrol memberi petunjuk ke solenoid untuk membuka katup sehingga bahan bakar mengalir melalui pipa utama ke ujung tungku. Pada saat ini mulai terjadi pembakaran dengan api besar disertai dengan api kecil yang bersumber dari pipa kapiler.

- Proses pembakaran melalui pipa utama (api besar) akan dihentikan secara otomatis jika suhu yang diinginkan atau di set-up telah tercapai. Pada kondisi ini, api pada pipa kapiler tetap menyala untuk mencegah penurunan suhu.

- Sebaliknya, jika suhu mulai turun, sistem kontrol akan memberikan petunjuk ke solenoid untuk membuka katup agar terjadi proses pembakaran. Mekanisme ini berlangsung secara kontinyu sehingga tidak terjadi bias dari suhu yang di set-up.

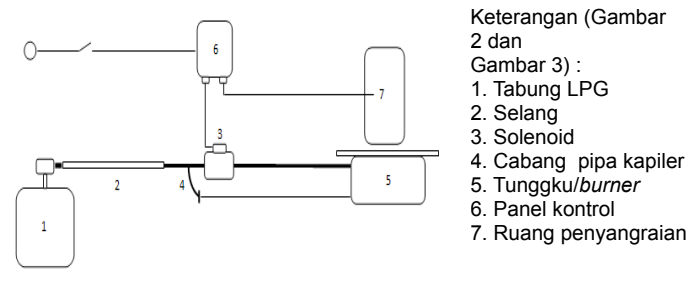

Gambar 2. Skema Instalasi Regulator Otomatis untuk Penyangraian Biji Kopi dan Kakao

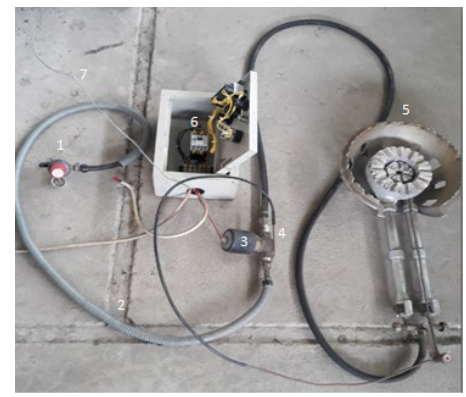

Gambar 3. Hasil Perakitan Regulator yang terhubung dengan Piranti kontrol dan Burner

\section{Aplikasi dan Kinerja Sistem}

Penerapan tungku dengan sistem pembakaran terkontrol pada proses penyangraian dalam kondisi tanpa bahan (kopi dan kakao) menunjukkan bahwa sistem pembakaran ini dapat bekerja secara otomatis pada suhu set point 100, 120, 140, 160, 180, 200 dan $220{ }^{\circ} \mathrm{C}$ dengan waktu capaian antara 5-15 menit. Hasil perhitungan menggunakan persamaan (1) menunjukkan bahwa, kinerja sistem pembakaran pada proses penyangraian dengan suhu 100,120 dan $140{ }^{\circ} \mathrm{C}$, terjadi bias suhu 1 (satu) ${ }^{\circ} \mathrm{C}$, pada suhu 160, 180 dan $200{ }^{\circ} \mathrm{C}$ terjadi bias suhu sebesar $2{ }^{\circ} \mathrm{C}$ dan pada suhu $220^{\circ} \mathrm{C}$ terjadi bias suhu $3^{\circ} \mathrm{C}$ (Gambar 5). Tampaknya semakin tinggi suhu semakin besar bias, hal ini menunjukkan bahwa suplai energi panas lebih tinggi dari pada yang dibutuhkan (penyangraian tanpa 
bahan) sehingga pengendalian melalui respon sensor menjadi lambat. Upaya pengendalian kondisi ini dapat dilakukan dengan mengatur volume sumber gas yang menghasilkan energi panas dengan sistem kontinyu maupun energi panas dengan sistem terputus (tidak langsung). Selain itu, pemilihan sensor dengan kepekaan tinggi merupakan pertimbangan jika secara ekonomis menguntungkan.

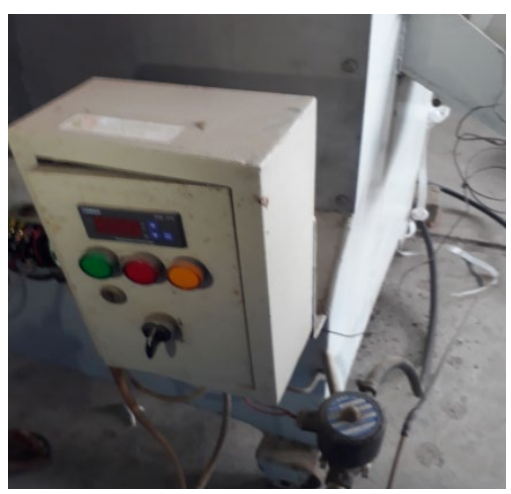

Gambar 4. Regulator Terpasang pada Alat Penyangraian

Namun secara umum menunjukkan bahwa penggunaan tungku dengan sistem pembakaran yang terkontrol pada alat penyangraian menghasilkan proses kinerja yang sangat efektif, dimana terdapat efektivitas kinerja dengan bias suhu yang kecil yaitu 1-3 ${ }^{\circ} \mathrm{C}$. Dilihat dari performa sistem pembakaran yang dikembangkan maka penggunaan suhu 100-140 ${ }^{\circ} \mathrm{C}$ lebih umum digunakan untuk menyangrai biji-bijian jenis kakao, kedelai dan kacang-kacangan. Khusus untuk kakao, penggunaan suhu dibawah $\quad 100{ }^{\circ} \mathrm{C}$ bertujuan untuk mempertahankan kualitas senyawa fungsional dan lemak atau minyak sedangkan suhu diatas $100^{\circ} \mathrm{C}$ sampai $140^{\circ} \mathrm{C}$ bertujuan untuk menghasilkan kakao dengan aroma yang kuat. Selain itu, terdapat metode penyangraian kakao yang menggunakan suhu rendah $100{ }^{\circ} \mathrm{C}$ pada tahap awal kemudian diikuti oleh tahap lanjutan yang penggunaan suhu tinggi antara $125-135^{\circ} \mathrm{C}$. Pada beberapa penyangraian dengan metode batch, suhu dapat mencapai $150^{\circ} \mathrm{C}$ atau lebih (Minifie, 1999). Secara umum, penggunaan suhu $100-140{ }^{\circ} \mathrm{C}$ pada penyangraian atau penggorengan biji-bijian seperti kedelai atau kacang dengan waktu tertentu dapat mematangkan bahan, mengurangi kadar air, mematikan mikroba dan dapat mempermudah proses pengupasan kulit.

Penggunaan suhu $180-220^{\circ} \mathrm{C}$ lebih umum digunakan untuk menyangrai atau menggoreng biji kopi. Menurut National Coffee Association (1911) penggorengan kopi pada suhu $180-195{ }^{\circ} \mathrm{C}$ menghasilkan kopi dengan kualitas light roast. Biji kopi dengan kualitas medium roast dihasilkan dari penyangraian dengan suhu $200-210{ }^{\circ} \mathrm{C}$ sedangkan penyangraian dengan suhu 220$250{ }^{\circ} \mathrm{C}$ menghasilkan biji kopi dengan warna gelap (dark roast). Dilihat dari tiga jenis kualitas kopi ini, hanya dua jenis kualitas kopi yang dapat diproses dengan menggunakan sistem pembakaran terkontrol yaitu jenis light roast $\left(180-195^{\circ} \mathrm{C}\right.$ ) dan medium roast $\left(220-250^{\circ} \mathrm{C}\right.$ ) sedangkan penggunaan suhu diatas $220^{\circ} \mathrm{C}$ untuk menghasilkan jenis kopi dengan kualitas dark roast (warna gelap) masih perlu kajian lebih lanjut.

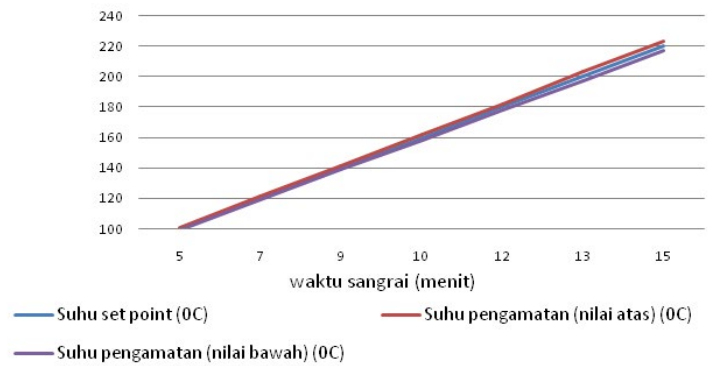

Gambar 5. Suhu set point dan besaran bias suhu selama penyangraian menggunakan regulator otomatis saat diuji tanpa bahan

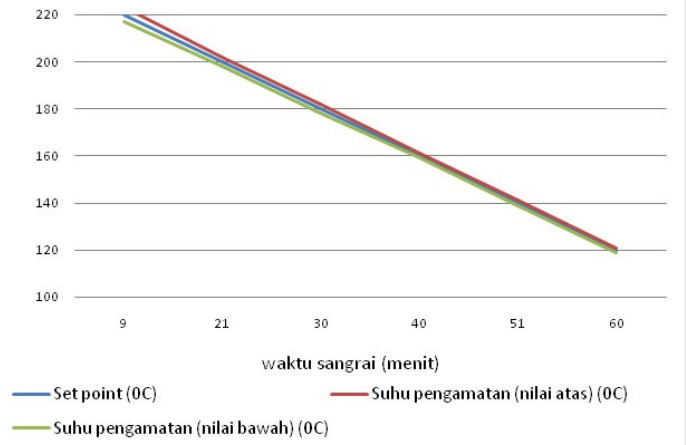

Gambar 6. Suhu set point dan besaran bias suhu selama penyangraian biji kopi menggunakan regulator otomatis 


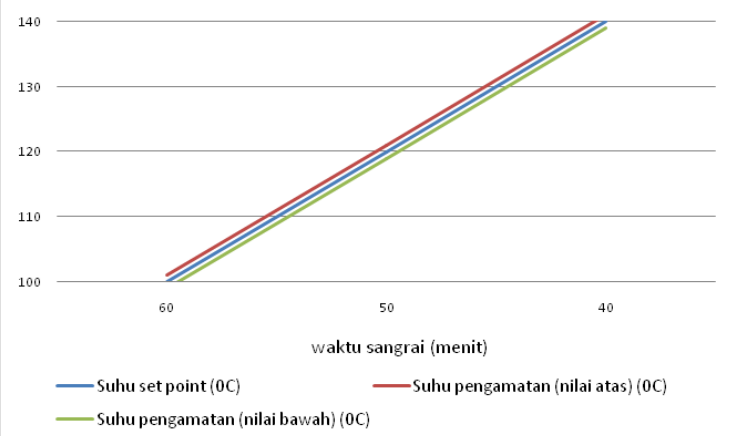

Gambar 7. Suhu set point dan besaran bias suhu selama penyangraian biji kakao menggunakan regulator otomatis

Uji kinerja tungku dengan sistem pembakaran terkontrol untuk penggorengan biji kopi menunjukkan bahwa dibutuhkan waktu penggorengan lebih cepat sejalan dengan pertambahan suhu. Hasil perhitungan dari persamaan (1) menunjukkan bahwa, penggorengan kopi pada suhu $120-160{ }^{\circ} \mathrm{C}$ selama 40-60 menit menyebabkan terjadi bias suhu $1^{\circ} \mathrm{C}$ dan penggorengan di atas $160{ }^{\circ} \mathrm{C}$ sampai $220{ }^{\circ} \mathrm{C}$ terjadi bias suhu $2-3$ ${ }^{\circ} \mathrm{C}$ (Gambar 6). Terjadinya bias suhu $1-3^{\circ} \mathrm{C}$ menunjukkan kinerja tungku pembakaran bekerja dengan baik untuk penggorengan kopi dengan berat $10 \mathrm{~kg}$. Bias suhu menunjukkan terjadi ketidakseimbangan antara suplai energi panas dengan jumlah bahan yang disangrai. Pada suhu yang lebih tinggi $\left(180-220^{\circ} \mathrm{C}\right)$ suplai energi panas yang berlebihan tidak dapat dikendalikan oleh sistem kontrol, hal ini menyebabkan beban/ kinerja sistem kontrol menjadi lebih besar. Upaya meminimalkan bias suhu dapat dilakukan dengan menyesuaikan jumlah bahan yang disangrai dengan suplai energi panas, dimana suplai energi yang berlebihan dapat dimanfaatkan dengan menaikkan jumlah bahan yang akan disangrai. Pada kondisi ini, bahan (kopi) dengan berat di atas $10 \mathrm{~kg}$ diperkirakan dapat menyerap kelebihan energi panas yang dihasilkan dari sistem pembakaran yang dirancang. Penyangraian kopi pada suhu $120-160{ }^{\circ} \mathrm{C}$ selama $40-60$ menit menghasilkan kopi dengan kadar air $4,15 \%$ dari kadar air awal 12\%, warna kekuningan hingga cokelat muda dengan aroma kopi ringan. Sedangkan penyangraian pada suhu $180-220^{\circ} \mathrm{C}$ menghasilkan kadar air 1,27-2,31\%, warna cokelat hingga cokelat kehitaman dengan aroma khas kopi sedang, kuat hingga ringan (Tabel 2).

Aplikasi pada penyangraian biji kakao menunjukkan kinerja sistem pembakaran lebih baik dan stabil, karena sistem ini bekerja pada suhu $100-140^{\circ} \mathrm{C}$ yaitu kisaran suhu yang dibutuhkan untuk penyangraian biji kakao (Gambar 7). Sehingga dapat dinyatakan bahwa sistem ini sangat ideal untuk penyangraian biji kakao. Dilaporkan oleh Ziegleder (2009), umumnya kakao disangrai pada suhu 120 dan $140{ }^{\circ} \mathrm{C}$, dimana lebih rendah dari suhu penyangraian kacangkacangan atau kopi. Walaupun demikian penyangraian dengan sistem ini juga sudah cukup ideal untuk dioperasikan pada suhu $180-220^{\circ} \mathrm{C}$. Proses penyangraian kakao pada suhu 120 dan $140{ }^{\circ} \mathrm{C}$ menghasilkan kadar air sebesar 3,15\% dan 2,89\% dengan warna dan aroma khas kakao (Tabel 2).

Penerapan sistem kontrol suhu dengan bias yang kecil dan pengendalian sistem perapian maupun pengendalian penggunaan bahan bakar secara terbatas pada sistem ini memungkinkan tercapainya efisiensi dan konsistensi mutu produk yang dihasilkan.

Uji kebutuhan dan efisiensi energi panas (Tabel 1) berdasarkan persamaan (2, 3 , dan 4) menunjukkan bahwa suplai energi panas berkisar antara $10.977-11.821,78 \mathrm{kcal}$ pada suhu $180{ }^{\circ} \mathrm{C}$ dan $220{ }^{\circ} \mathrm{C}$ yang berasal dari $0,975-1,075 \mathrm{~kg}$ LPG, dan pada suhu 160 ${ }^{\circ} \mathrm{C}$ suplai energi panas sebesar 12.371,63 kcal yang berasal dari $1,125 \mathrm{~kg}$ LPG. Pada suhu $120^{\circ} \mathrm{C}$ dan $140^{\circ} \mathrm{C}$, suplai energi panas masing-masing adalah sebesar 13.966,19 kcal dan 13.471,33 kcal. Nilai energi panas untuk penyangraian kakao ini lebih besar dari energi yang dibutuhkan untuk penyangraian kopi karena proses penyangraian kakao membutuhkan waktu yang lebih lama. 
Tabel 1. Kebutuhan dan efisiensi energi pada berbagai suhu penyangraian kopi dan Kakao menggunakan regulator otomatis.

\begin{tabular}{|c|c|c|c|c|c|c|c|c|}
\hline \multicolumn{9}{|l|}{ KOPI } \\
\hline \multicolumn{2}{|c|}{ Suhu } & \multirow{2}{*}{$\begin{array}{l}\text { Massa } \\
\text { LPG } \\
(\mathbf{k g})\end{array}$} & \multirow{2}{*}{$\begin{array}{l}\text { Waktu } \\
\text { sangrai } \\
\text { (menit) }\end{array}$} & \multirow{2}{*}{$\begin{array}{l}\text { Massa } \\
\text { Kopi } \\
\text { (setelah } \\
\text { sangrai) } \\
\text { (kg) }\end{array}$} & \multirow{2}{*}{$\begin{array}{l}\text { Panas } \\
\text { yang } \\
\text { dihasilkan } \\
\left(Q_{\text {in }}\right) \text { (kcal) }\end{array}$} & \multirow{2}{*}{$\begin{array}{l}\text { Panas yang } \\
\text { dibutuhkan } \\
\left.\left(Q_{1}+Q_{2}\right)\right) \\
\text { (kcal) }\end{array}$} & \multirow{2}{*}{$\begin{array}{l}\text { Efisiensi } \\
\text { perpindahan } \\
\text { panas, } E_{h t} \\
(\%)\end{array}$} & \multirow{2}{*}{$\begin{array}{l}\text { Efisiens } \\
\text { termal, } \\
E_{t}(\%)\end{array}$} \\
\hline $\begin{array}{l}\text { Set } \\
\text { point } \\
\left({ }^{\circ} \mathrm{C}\right)\end{array}$ & $\begin{array}{l}\text { Suhu } \\
\text { awal } \\
\left({ }^{\circ} \mathrm{C}\right)\end{array}$ & & & & & & & \\
\hline 160 & 80 & 1,125 & 40 & 7,8 & $12.371,63$ & $1.532,96$ & 62,50 & 12 \\
\hline 180 & 80 & 1,075 & 30 & 7,2 & $11.821,78$ & $1.943,70$ & 67,57 & 16 \\
\hline 200 & 80 & 1,000 & 20 & 6,5 & $10.997,00$ & $2.409,44$ & 71,43 & 21 \\
\hline 220 & 80 & 0,975 & 9 & 6,2 & $10.722,07$ & $2.655,18$ & 74,00 & 5,3 \\
\hline \multicolumn{9}{|c|}{ KAKAO } \\
\hline 120 & 80 & 1,270 & 45 & 8,2 & $13.966,19$ & $1.121,60$ & 45,40 & 8,03 \\
\hline 140 & 80 & 1,225 & 45 & 7,8 & $13.471,33$ & $1.407,40$ & 55,55 & 10 \\
\hline
\end{tabular}

Keterangan: Kapasitas panas spesifik biji kopi: $1,69 \mathrm{~kJ} / \mathrm{kg}{ }^{\circ} \mathrm{C}$ atau 0,4037 kcal (Mulato, 2002); kapasitas panas spesifik biji kakao: 0,1373 kJ/Kg ${ }^{\circ} \mathrm{K}$ atau 0,329 kcal (Mohas, 2010); kapasitas panas LPG: 10.997 $\mathrm{kcal} / \mathrm{kg}$ (The Engineering Toolbox, 2014-b)

Tabel 1 memperlihatkan hasil perhitungan efisiensi perpindahan panas dan efisiensi termal berdasarkan persamaan ( 5 dan 6) selama proses penyangraian kopi dan kakao menggunakan regulator otomatis. Diperoleh efisiensi perpindahan panas untuk proses penyangraian kopi pada suhu $160-220{ }^{\circ} \mathrm{C}$ adalah sebesar $62,50-74,00 \%$ dengan efisiensi termal $5,3-12 \%$. Sedangkan efisiensi perpindahan panas dalam proses penyangraian kakao adalah sebesar 45,40 $55,55 \%$ dengan efisiensi termal 8,03$10,00 \%$. Hal ini menunjukkan bahwa, masih terdapat kehilangan energi panas sebesar $30-40 \%$ dalam proses penyangraian kopi dan $40-50 \%$ dalam proses penyangraian kakao. Namun demikian dapat diprediksi bahwa volume dan kapasitas sangrai dapat ditingkatkan untuk mengoptimalkan penggunaan energi panas yang dihasilkan oleh sistem pembakaran dengan regulator otomatis. Selain itu, sistem yang digunakan pada instalasi regulator ini dapat diatur besar kecilnya volume bahan bakar sehingga pada pengaturan (set-up) yang tepat akan mengoptimalkan penggunaan energi. 
Tabel 2. Karakteristik Kopi dan Kakao pada Berbagai Suhu Penyangraian

\begin{tabular}{|c|c|c|c|c|c|c|c|}
\hline KOPI & KAKAO & & & & & & \\
\hline Suhu & Kadar Air (\%) & Warna & Aroma & Suhu & $\begin{array}{l}\text { Kadar } \\
\text { Air (\%) }\end{array}$ & Warna & Aroma \\
\hline & - & - & & 120 & 3,15 & Cokelat & $\begin{array}{c}\text { Aroma khas } \\
\text { cokelat }\end{array}$ \\
\hline & - & - & & 240 & 2,89 & Cokelat & $\begin{array}{c}\text { Aroma Khas } \\
\text { cokelat }\end{array}$ \\
\hline 160 & 4,15 & Kekuningan & $\begin{array}{l}\text { Aroma } \\
\text { kopi rin- } \\
\text { gan }\end{array}$ & - & - & - & - \\
\hline 180 & 2,31 & Cokelat & $\begin{array}{c}\text { Aroma } \\
\text { kopi kuat }\end{array}$ & - & - & - & - \\
\hline 200 & 1,86 & $\begin{array}{l}\text { Cokelat } \\
\text { gelap }\end{array}$ & $\begin{array}{l}\text { Aroma } \\
\text { kopi se- } \\
\text { dang }\end{array}$ & - & - & - & - \\
\hline 220 & 1,27 & $\begin{array}{c}\text { Cokelat } \\
\text { gelap agak } \\
\text { kehitaman }\end{array}$ & $\begin{array}{l}\text { Aroma } \\
\text { kopi rin- } \\
\text { gan }\end{array}$ & - & - & - & - \\
\hline
\end{tabular}

\section{KESIMPULAN}

Regulator yang dikembangkan untuk alat penyangraian kopi dan kakao menghasilkan proses kinerja yang sangat efektif, dimana terdapat efektivitas kinerja dengan bias suhu yang kecil yaitu 1-3 ${ }^{\circ} \mathrm{C}$ pada suhu $100-220^{\circ} \mathrm{C}$. Aplikasi pada penyangraian kopi dan kakao menghasilkan proses penyangraian yang ideal pada kapasitas $5-10 \mathrm{~kg}$ dengan bias suhu $1^{\circ} \mathrm{C}$ pada suhu $100-140{ }^{\circ} \mathrm{C}$ dan bias $2-3^{\circ} \mathrm{C}$ pada suhu $200-220{ }^{\circ} \mathrm{C}$. Efisiensi perpindahan panas berkisar antara $0,625-0,74$ atau 62,5-74\% untuk penyangraian kopi dan 0,40,55 atau $45,4-55,55 \%$ untuk penyangraian kakao sedangkan efisiensi termal untuk penyangraian kopi mencapai 0,05-0,12 atau $5-12 \%$ dan untuk penyangraian kakao adalah 0,08-0,10 atau 8-10\%.

Sistem pembakaran ini dapat diaplikasikan untuk proses penyangraian kopi secara konsisten pada $200-220^{\circ} \mathrm{C}$ dan untuk penyangraian kakao pada $120-140{ }^{\circ} \mathrm{C}$.

\section{DAFTAR PUSTAKA}

EMT, 2014. Best Practice Manual: Dryers. Energy Manager Training. www. Energymanagement.training.com (diakses 04 Juni 2014)
Fellows, PJ. 2000. Food Processing Technology: Principle and Practice. 2 nd Ed. Cambridge UK: Wood Head Pub

Lestari, Puji. 2016. Teknologi Pengolahan Kopi. diakses pada 16 April 2016

Minifie, BW. 1999. Chocolate, Cocoa and Convectionary. Science and Technology, Westport Conecticut: AVI Pub.

Mohas, F. 2010. Convectionary and Chocolate Engineering: Principles and Applications. lowa: Wiley-Blackwell.

Mulato, S. 2002. Perancangan dan Pengujian Mesin Sangrai Biji Kopi Tipe Silinder. Pelita Perkebunan 2012, 18 (1), 31-45.

National Coffee Association USA EST, 1911. Coffee Roast.

Schwartzberg, HG. 2015. Evolution of Coffee Roasting. Annual Meeting Food Engineering. University of Massachusetts.

Schwartzberg, HG. 2013. Batch Coffee Roasting; Roasting Energy Use; Reducing That Use. Advances in Food Process Engineering Research and Applications. Food Engineering Series. 2013:173-193. 
Srivastava, A.C. Techniques of Instrumentation. Vani Education Books.

Subrahmanyam, V. 1994. Electric Drives. Concepts and Applications. Tata McGraw-Hill Publishing Company Limited. New Delhi

Suharto, 1991. Teknologi Pengawetan Pangan. Jakarta: Aneka Cipta
The Engineering Toolbox. 2014-b. Gross and Net Heating Values for Some Common Gases. www.engineering. Toolbox.com Ziegleder, G. 2009. Flavor Development of Cocoa and Chocolate in Industrial Manufacture and Uses (Ed. St. Becket). 